\title{
What Is the Personal Experience of IBD Patients about Their Anti-TNF-Alpha Therapy?
}

\author{
Ágnes Milassin', Mariann Rutka1, Ágnes Anna Csontos², Pál Miheller², Károly Palatka3,

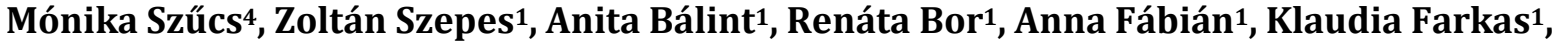 \\ Ferenc Nagy ${ }^{1}$, Tamás Molnár ${ }^{1 *}$
}

\author{
${ }^{1}$ First Department of Medicine, University of Szeged, Szeged, Hungary \\ ${ }^{2} 2^{\text {nd }}$ Department of Medicine, Semmelweis University, Budapest, Hungary \\ ${ }^{3} 2^{\text {nd }}$ Department of Internal Medicine, University of Debrecen, Debrecen, Hungary \\ ${ }^{4}$ Department of Medical Physics and Informatics, University of Szeged, Szeged, Hungary \\ Email: *molnar.tamas@med.u-szeged.hu
}

How to cite this paper: Milassin, Á., Rutka, M., Csontos, Á.A., Miheller, P., Palatka, K., Szűcs, M., Szepes, Z., Bálint, A., Bor, R., Fábián, A., Farkas, K., Nagy, F. and Molnár, T. (2017) What Is the Personal Experience of IBD Patients about Their AntiTNF-Alpha Therapy? Health, 9, 1007-1018. https://doi.org/10.4236/health.2017.97073

Received: February 27, 2017

Accepted: July 7, 2017

Published: July 10, 2017

Copyright $\odot 2017$ by authors and Scientific Research Publishing Inc. This work is licensed under the Creative Commons Attribution International License (CC BY 4.0).

http://creativecommons.org/licenses/by/4.0/

\begin{abstract}
AIM: To evaluate and compare the patients opinion on the two types of antiTNF- $\alpha$ therapies in a Hungarian cohort of IBD patients. METHODS: This was a prospective, multicentre, questionnaire-based observational study carried out in three Hungarian tertiary centres. From April to September 2014, an anonymous questionnaire was distributed to patients diagnosed with ulcerative colitis (UC) or Crohn's disease (CD), who have received infliximab (IFX) and/or adalimumab (ADA). The survey focused on the preferences of the two anti-TNF- $\alpha$ therapies on the basis of the efficacy, the administration routes and the side-effects. RESULTS: 292 IBD patients, 216 CD, 75 UC and 1 indeterminate colitis patient completed the questionnaire. The mean duration of biological therapy was $1.7(1-7)$ years. IFX treated patients noticed improvement of symptoms at $4-5$ weeks while ADA treated patients noticed at 5 - 6 weeks. There was no difference between the patients' satisfaction regarding the types of anti-TNF- $\alpha$ therapy if they received both. However, subcutaneous administration was preferred by ADA-treated patients previously receiving IFX $(\mathrm{p}=0.007)$ compared to intravenous route and they did not intend to change the mode of therapy $(p=0.040) .90 \%$ of the patients, receiving only IFX or ADA were satisfied with their present therapy. The majority of patients $(186 / 292,63.7 \%)$ would not switch therapy. 63 of $291,22 \%$ of the patients reported to have some concern with biological therapy-the majority $(32 / 63,50.8 \%)$ due to fear from side effects. CONCLUSION: Generally, patients preferred and would not change the present anti-TNF- $\alpha$ therapy, however, subcutaneous administration was preferred among those patients who had have experience with both.
\end{abstract}




\section{Keywords}

Patient's Satisfaction, Personal Experience, Questionnaire, Anti-TNF-Alpha Therapy, Patient's Preference

\section{Introduction}

Inflammatory bowel disease (IBD) is a chronic inflammatory intestinal disorder defined clinically into two major entities: Crohn's disease (CD) and ulcerative colitis (UC). These diseases can affect the entire gastrointestinal tract [1]. While the exact etiopathogenesis of the disease remains unknown, it is widely accepted that both CD and UC originate from an inappropriate immune response in genetically susceptible individuals as a result of complex interactions of genetic, environmental and microbial factors [2]. These conditions usually require a lifelong treatment because of the complex, uncertain and chronic nature of the disease. The goal of the treatment in the management of IBD is not only to achieve clinical improvement but also to alter the course of disease and to restore a normal bowel function. This requires the suppression of inflammation and the induction of complete mucosal healing [3] [4]. With the early use of biological agents, these treatment goals can now be achieved. Infliximab (IFX) and adalimumab (ADA) are the two firstly and most widely used anti-TNF- $\alpha$ biological therapies licensed for the treatment of IBD (CD and/or UC) in Europe. In 1997, IFX was the first biological agent used for the treatment of moderate to severe $\mathrm{CD}$ in patients with inadequate response to corticosteroid and/or immunosuppressant therapy, or who could not tolerate the side effects or had contraindications. Later IFX was subsequently used for the treatment of UC in similar indications. The recommended dose of IFX is $5 \mathrm{mg} / \mathrm{kg}$ given as an intravenous induction regimen at first, second and sixth week followed by a maintenance regimen of $5 \mathrm{mg} / \mathrm{kg}$ every eighth week. Patients have to spend time on treatment, because of waiting for blood test and for IFX infusion therapy at outpatient clinic. An infusion is given approximately over 2 hours, after that they have to stay for clinical observation in case of late infusion reactions occurred. ADA has been available in Hungary since 2007 and in contrast to IFX, and it is administered as a subcutaneous injection usually every other week, at dose of 160 $\mathrm{mg}, 80 \mathrm{mg}$ for induction and subsequently $40 \mathrm{mg}$ every other week for maintenance. This subcutaneous injection can be administered by general practitioner, nurse or by the patient after learning self-injection technique. Self-administration requires high cooperation and compliance from patients. Clinical indications of these two anti-TNF agents are similar.

On several occasions during IBD therapy can patient and doctor make decisions, but how they decide? The decision about which one of the two anti-TNF agents receive the patient depends on the specialist's recommendation and the patient's preference. Allen $\mathrm{PB}$ et al. found a trend towards patient preference for IFX (iv.) treatment as opposed to ADA (sc.) [5]. They found the difference may 
be due to the frequency of administration, mode of administration or differing 'times in the market-place' [5]. Contrary Vavricka et al. found that patients preferred anti-TNF medications that were administered by subcutaneous injection rather than by intravenous infusion [6]. The two major factors influencing patient's decision were the ease of use and the time required for therapy [6]. The aim of this study was to evaluate and compare the patients' opinion and satisfaction with the two types of anti-TNF- $\alpha$ therapies a Hungarian cohort of IBD patients.

\section{Materials and Methods}

This was a prospective, multicentre, questionnaire-based observational study carried out in three Hungarian tertiary centres. Adult patients diagnosed with UC or CD, who have administered at the time of the study or previously one or both of the two anti-TNF agents and performed anonymously questionnaire- based survey between April 2014 and September 2014, were enrolled in the study (Appendix 1). Patients who did not meet the above-mentioned inclusion criteria were excluded. The questionnaire contained questions for patient's demographic data (gender, age, smoking history and patients' highest educational level), IBD characteristics (year of diagnosis, disease phenotype, disease location, IBD related operations, concomitant medications), and further questions were about patients' preferences for anti-TNF drugs. Specifically, patients were asked about current and/or previous biological therapy, and the satisfaction in accordance with the current anti-TNF- $\alpha$ therapy. If they changed therapy, the reason and the satisfaction with previous or current therapy was also asked. Questions were about the price supposed of the biological agent they received, when and from who they heard first about biological treatment, their worst experience during biological therapy, the side effects they noticed and whether they were anxious of biological therapy. Further questions were about the time after they felt improvement of their symptoms, if they have ever observed that the efficacy of biological therapy decreased before the next maintenance therapy. Further questions were: "Which biological agent would you prefer based on your experience if you can choose"; "What was the most effective therapy you have ever received"; "Have you been operated during biological therapy?". Finally, patients were asked if they would participate in a new drug trial even though they would have to stop their current biological treatment or not.

\section{Statistics}

The collected data were analysed statistically. Data were analysed using Pearson's chi-square test, and Fisher exact test. $\mathrm{P}<0.05$ was considered statistically significant. For the statistical analysis, R statistical program (version 3.2.5) was used.

\section{Ethical approval}

The study was approved by the Regional and Institutional Human Medical Biological Research Ethics Committee of the University of Szeged. 


\section{Results}

\section{Patients Characteristics}

Two hundred and ninety-two IBD patients (133 women, 159 men, mean age 35 (15 - 67) years) were prospectively enrolled. Table 1 gives an overview of the

Table 1. Baseline Characteristics of Patients.

\begin{tabular}{cc}
\hline Item & Frequency \\
\hline Number of patients & 292 \\
Females/males & $133 / 159$ \\
Age (years; mean $\pm \mathrm{SD})$ & $35 \pm 11.4$, range $15-67$ \\
$\mathrm{CD} / \mathrm{UC} /$ not determined & $216 / 75 / 1$
\end{tabular}

Crohn's disease location

$\begin{array}{llc}\text { L1 } & \text { ileum } & 13 \% \\ \text { L2 colon } & 31 \% \\ \text { L3 } & \text { ileocolonic } & 49.5 \% \\ & \quad \text { not responded } & 6.5 \%\end{array}$

Crohn's disease, disease duration (yrs)

$\begin{array}{lc}<1 \text { year } & 0 \% \\ 1-5 \text { years } & 32.4 \% \\ >5 \text { years } & 65.3 \% \\ \text { not responded } & 2.3 \%\end{array}$

UC patients disease extent

$\begin{array}{lc}\text { proctitis } & 16.2 \% \\ \text { left sided colitis } & 29.7 \% \\ \text { pancolitis } & 55.4 \% \\ \text { not responded } & 2.7 \%\end{array}$

Ulcerative colitis, disease duration (yrs)

$\begin{array}{lc}<1 \text { year } & 0 \% \\ 1-5 \text { years } & 34.7 \% \\ >5 \text { years } & 65.3 \%\end{array}$

Active smokers

$\mathrm{CD}$

$17 \%$

UC $10.7 \%$

Educational level

$\begin{array}{lc}\text { No education } & 0 \% \\ \text { Elementary school } & 7.2 \% \\ \text { High school } & 46.9 \% \\ \text { Apprenticeship and college program } & 31.5 \% \\ \text { University degree } & 11.3 \% \\ \text { Not responded } & 3.1 \%\end{array}$


patient characteristics. Disease phenotype was determined in accordance with Montreal Classification [7]. The mean disease duration was $9.32 \pm 6.63$ years in $\mathrm{CD}$ patients and $11 \pm 7.92$ years in UC patients. The majority of patients (141/216, 65.3\% of CD patients, 49/75, 65.3\% of UC patients) have long-standing disease (disease duration $>5$ years). 141 of $292,48.3 \%$ of patients were nonsmoker (93/216, 43.1\% of CD patients; 48/75, 64\% of UC patients), 100 of 292, $34.2 \%$ were ex-smoker, 45 of 292, 15.4\% were current smoker, while 6 of 292, $2.1 \%$ of patients have not responded. One hundred and twenty patients have ever required IBD related surgical intervention in an average 2.87, (1 - 12) times.

\section{IBD-related medication}

259 patients have received one of the biological treatments at the time of the survey. 153 were receiving IFX and $106 \mathrm{ADA}$. At the time of the survey $33 \mathrm{pa}-$ tients have already finished their biological therapy. 137 of $259,52.9 \%$ of those patients who have received one of the biological therapies at the time of the survey were on concomitant medications (5-aminosalicylates: 25/137, 18.2\%; steroids: $16 / 137,11.7 \%$; thiopurine: $41 / 137,30 \%$; antibiotics: $4 / 137,2.6 \%$; not responded: $77 / 137,56.2 \%)$. The mean duration of biological therapy was 1.7 years (in range 1 - 7 years). The majority of the patients have received only IFX currently or previously $(168 / 292,57.5 \%) ; 79$ of $292,27 \%$ of the patients have had experience with both anti-TNF agents, majority of them $(68 / 79,86 \%)$ switched from IFX to ADA, while only 45 of 79, 15.4\% of the patients received only ADA (currently or previously). The main reason of switching anti-TNF agents mentioned by the patients was lack of efficacy $(31 / 79,39 \%)$, allergy $(25 / 79,31 \%)$ and other complications like arthralgia or thrombocytopenia.

\section{Patients Satisfaction with Biological Therapy}

The majority of the patients $(259 / 292,88 \%)$ treated with biological therapy were satisfied with their management (138/153, 90\% of IFX; 90/106, 84\% of ADA treated patients). 33 of $292,12 \%$ of the patients were unsatisfied with their therapy, they mentioned lack of efficacy, side effects (joint and bone pain), and 6 of them did not answer to the question. 79 patients had experiences with both biological agent, majority of them $(33 / 79,42 \%)$ was more satisfied with ADA treatment, they mentioned that ADA is more effective, they were satisfied with the ease of use and less side effect of ADA. 15 of 79, 19\% of the patients was content with IFX because of its effectiveness. According to the patients' decision biological therapy was the most effective treatment ever. 181 of $292,62 \%$ of them found biological therapy the most effective therapy ever received. Other treatment like steroid $(32 / 292,11 \%)$, thiopurine $(15 / 292,5.1 \%)$ was also found effective. Important to note, that 70 of $292,24 \%$ of the patients did not fulfil this question.

Patients treated with IFX felt the effectiveness of the therapy at first time between the $4-5^{\text {th }}$ week, while patients on ADA therapy felt it between the 5- $6^{\text {th }}$ week. More than half of the patients felt ever loss of effectiveness before the next regular infusion/injection. 268 patients replied on this question, 168 received IFX, 100 received ADA. Almost 60\% (102/168) of those patients who were on 
IFX marked feeling loss of effectiveness, while on ADA that percentage was 51\% (51/100).

\section{Do patients want to switch therapy?}

We asked from the patients: "If you could choose from biological treatments, which would you choose?". 116 of 292, 39.7\% of the patients chose IFX, 85 of 292, 29.5\% chose ADA, 2 of 292, 0.65\% chose both and 2 of 292, 0.65\% chose none of the biological agents. 87 of $292,29.5 \%$ of the patients did not respond to the question. 100 of 168 IFX treated patients (note, that 63 not responded) would choose IFX again and they mentioned: "This treatment is effective for me"; "I have no experiences with other biological therapy"; " I prefer to take drug less often"; "I don't like the idea of self-injecting"; "fewer side effects"; "medical supervision during infusion". 29 of 45 only ADA treated patients (note that 15 not responded) would choose ADA again and they mentioned: "This treatment is effective for me", "I have no other experiences with other biological agents"; "It is more comfortable for me to give the injection at home". The reasons cited for those patients who had experience with both anti-TNF- $\alpha$ agents and chose IFX (and the latest biological therapy was IFX), were: "This is more effective and I can feel the effect quicker than other biological agent" $(n=12)$, "I prefer to take drug less often" $(n=1)$. Significantly ( $p=0.007)$ more from those patients, who had experiences with both anti-TNF- $\alpha$ agents and the latest biological therapy was ADA, chose ADA, and the reasons mentioned were: "I prefer the convenience of self-injecting at home and I don't have to wait so much." (n= $17)$, “This treatment is effective for me" $(n=15)$, fewer side effects $(n=10)$. From them who chose IFX they mentioned "IFX was more effective" and they liked the infusion's frequency.

\section{Mode of administration}

Questions were about the patients' current treatment and about the mode of administration. In case of the current treatment was IFX $(n=179)$, the majority of the patients were satisfied with the infusion's time, and length of the therapy (150/179, 84\%), while the mode of administration did not disturb them (163/ $179,91 \%)$. They were asked whether they prefer the administration of IFX subcutaneously, like ADA, and 127 of $179,71 \%$ were satisfied with the current intravenous mode of administration. In case of the current treatment was ADA (n $=113$ ), the majority of the patients were satisfied with the subcutaneous mode of administration and with the therapy's frequency and did not disturb them (101 of $113,89 \%-89 \%)$. Who gives the subcutaneous injection was also asked: the majority of the patients give the injection themselves $(76 / 113,67 \%)$, in other cases the injection is given by a family member or general practitioner $(16 / 113$, $14 \% ; 14 / 113,12 \%)$. The majority of the patients were satisfied with the mode of administration and they would not change it. There was no difference between the patients' satisfaction regarding the type of anti TNF- $\alpha$ therapy if they received both. However, subcutaneous administration was preferred by ADAtreated patients, previously receiving IFX $(\mathrm{p}=0.007)$ compared to intravenous route and they do not intend to change the mode of administration of the ther- 
apy $(\mathrm{p}=0.043)$.

\section{Side effects and fears of biological therapy}

Seventy-two patients (from 267 respondents) noticed side effect of biological therapy during their treatment period, 57 patients were on IFX, and 10 were on ADA, while 1 patient experienced side effect with both anti-TNF $\alpha$ therapy. 195 of $267,73 \%$ of respondents haven't mentioned any side effect during biological therapy. Allergic or infusion reaction was mentioned by 27 patients ( 26 of 27 , $96 \%$ was on IFX, 1 of $27,4 \%$ was on ADA), such as breathlessness, and angiooedema. Skin problems were occurred in 15 patients (12 were on IFX, 2 were on ADA, 1 was on both anti-TNF $\alpha$ agents) such as skin rash, itchy skin, dry skin, and skin sensitivity. Joint and/or muscle complaints or pain was mentioned by 13 patients (8 patients were on IFX, 3 patients were on ADA). Infections (Herpes Simplex Virus, Human Papilloma Virus, Mycobacterium tuberculosis, flu-like infection) occurred in 9 cases. 10 cases appeared tiredness, depression, headache, nausea, hair loss. Regarding adverse events there was no significant differences between ADA and IFX according to patients' opinion.

In the majority of the cases $(112 / 182,61.5 \%)$, patients did not mention any complaints with biological therapy. The rest of the patients had complaints about the time for waiting for the infusion and travelling to the Hospital (45/182, $24.7 \%)$, the side effects $(8 / 182,4.4 \%)$, the efficacy of the treatment $(8 / 182,4.4 \%)$, the administration of medicaments (fear from the sting of a needle, collapsed veins, pain from subcutaneous injection) and cooling the injection during travelling $(9 / 182,5 \%)$.

Patients mentioned adverse events $(29 / 228,12.7 \%)$, problems with administration $(21 / 228,9.2 \%)$, relapse of the disease $(8 / 228,3.5 \%)$ and the time for waiting $(6 / 228,2.6 \%)$ as the worst experience during the biological therapy.

According to our survey 63 of 291 patients, 21.65\% were anxious because of the biological therapy; adverse events may occur during treatment $(n=32)$, long term effects are unknown $(n=18)$, malignancies may develop $(n=2)$, infections can occur $(\mathrm{n}=2)$, treatment can affect pregnancy $(\mathrm{n}=1)$ were mentioned.

\section{Patients' knowledge about anti-TNF drugs}

Most of the patients collect information about their accurate medical therapy from their physician $(232 / 292,79.4 \%)$. Getting information from internet (14/ 292, 4.8\%), asking other patients or visiting patients forum (11/292, 3.7\%), friends $(8 / 292,2.7 \%)$, school $(1 / 292,0.4 \%)$ or television $(1 / 292,0.4 \%)$ were less frequently. Note, that 25 of $292,8.6 \%$ of the patients quitted this question.

Patients were also asked about what they think about one therapies price. The mean price of IFX was supposed to be approximately 635,000 HUF, while the official price was approximately 153,000 HUF. The mean price of ADA was supposed to be approximately 446,000 HUF, while the official price was approximately $275,000 \mathrm{HUF}$ at the time of the survey.

\section{Discussion}

In this prospective, multicentre observational study of the IBD patients' opinion 
and satisfaction about the currently available two anti-TNF drugs in Hungary were evaluated and a questionnaire based survey was used. Questionnaires were distributed between April 2014 and September 2014 among adult patients diagnosed with UC or CD and received separately IFX, ADA or both IFX and ADA after each other. Two-thirds of the patients included in the survey were on IFX therapy at the time of the study and $27 \%$ of the patients have been treated with both anti TNF agents.

Generally we found no significant differences in the patients' preferences for choosing one of the anti-TNF drugs (IFX or ADA). Our results showed that patients were satisfied with their current anti-TNF therapy; they found them effective therefore they did not want to change it to other anti-TNF medication with uncertain effect on their symptoms. Regarding those patients who were treated with both anti-TNF drugs, we found a tendency in preferring the currently used anti-TNF drugs. We found a tendency towards ADA treated patients like subcutaneous administration and they did not show a tendency to change it, while patients on IFX therapy, who were discontent with their therapy showed a tendency to change it to subcutaneous administration, and the time required for administration of IFX infusion was the main reason mentioned.

The majority of patients with IBD require long-term medication for disease control and maintenance of remission. Only limited data are available on the patients' knowledge and preference on biological therapy, although better cognition of the patients' opinion would improve the adherence to medications. $\mathrm{Pa}$ tient preference studies for anti TNF therapies are usually from the field of rheumatology. In rheumatoid arthritis studies, most patients prefer ADA to IFX because of the more convenient administration route of the drug [8] [9]. The main differences between IFX and ADA are the route of administration (hospital vs. self administered infusion/injection), frequency of dosing and the time on market. Although IFX has been licensed for a greater time on the market than ADA, both drugs have been used for years and proved their efficacy in the treatment of IBD. Frequency of dosing and route of administration are potentially modifiable factors of nonadherence to maintenance medication for IBD which occurs in $30 \%-45 \%$ of patients [10] [11]. Therefore adequately informing patients and considering their preference is important to improve adherence to therapy. The study by Selinger et al. revealed that patients on IFX were more adherent, than patients on ADA [11].

Several studies found that one anti-TNF drug is more preferred than other, but the results were controversial. Contrary to our data, in the study by Allen et al. nearly twice the number of patients chose IFX over ADA because of the lower frequency of dosing in $42 \%$ of the cases. The commonest reason cited for those who chose IFX (67\%) was that they did not like 'self-injecting administration' [5]. However, the study was not powered enough to draw significant conclusions and this difference did not reach statistical significance as well. In accordance with our results, they could not reveal any difference in preference for either anti-TNF therapy. Vavricka et al. evaluated the preferences of anti TNF naive CD 
patients for selecting one of the anti TNF drugs. Most patients preferred ADA and certolizumab pegol to IFX because of the ease of their subcutaneous administration and the reduced amount of time required to receive the therapy in comparison to anti-TNF drugs delivered by intravenous route [6]. Our findings on patient preferences for subcutaneous administration are comparable to preferences of rheumatoid arthritis patients and CD patients in the Vavricka study. However an important difference between our and Vavricka's study was that we included anti TNF experienced patients treated with either or both anti TNF drugs. Among patients who were treated with both agents, ADA was more preferred compared to IFX: patients found ADA to be more effective and they were satisfied with the ease of use and less side effects of the drug. Notably, patients treated with both agents were switched from IFX to ADA in $86 \%$ of the cases and the main reason of switching anti-TNF agents were loss of response and infusion reactions occurred during IFX therapy [6].

We found a tendency that patients treated with IFX felt the effectiveness of therapy earlier than patients treated with ADA but there were no significant differences between the two groups.

The limitation of the study was the relatively low response rates of certain parts of the survey despite the high number of enrolled patients. However, the study was able to demonstrate that the majority of the patients on biological therapy were satisfied with their management and found anti TNF therapy the most effective ever received. The majority of the patients received medical information from their physician suggesting an accurate knowledge about the therapies. $60 \%$ of IFX and $64 \%$ of ADA treated patients would choose their therapy again because they found them effective and do not have experience with the other agent. However, interviewed patients who preferred IFX stated that "I prefer to take drug less often" and "I don't like the idea of self-injecting" that determined the choice of therapy. The patients preferring ADA identified the comfortable route of giving the injection at home as a factor influencing their treatment choice.

Route and frequency of drug administration and side effects may play role in decision making of IBD patients. According to our results Hungarian IBD patients prefer subcutaneous administration because of its convenience and time saving property, but they also find both IFX and ADA effective. Our result suggest that beside the route of administration and the therapy's effect the key factors influencing a decision to choose a therapy for patients were physician's recommendation. Further studies are required in IBD patients to investigate whether patients' decision affect their compliance, satisfaction and effectiveness of anti-TNF therapies.

\section{Acknowledgements}

We would like to thank all the clinicians whose patients were included in the study.

Funding source: This paper was supported by the János Bolyai Research 
Scholarship of the Hugarian Academy of Sciences (BO/00632/13/5)

\section{Conflict of Interest}

The authors report no conflict of interest.

\section{Author Contributions}

Milassin Á, Rutka M contributed equally to this work and performed the research; Szepes Z, Farkas K, Nagy F contributed to study conception and design; Miheller P, Palatka K, Csontos Á A, Bor R, Bálint A, Fábián A contributed to data acquisition; Szücs $M$ contributed to data analysis and interpretation; Rutka M, Milassin Á wrote the paper; Farkas K, Molnár T contributed to editing, reviewing and final approval of article.

\section{References}

[1] Ananthakrishnan, A.N. (2013) Environmental Risk Factors for Inflammatory Bowel Disease. Journal of Gastroenterology and Hepatology, 9, 367-374.

[2] Xavier, R.J. and Podolsky, D.K. (2007) Unravelling the Pathogenesis of Inflammatory Bowel Disease. Nature, 448, 427-434. https://doi.org/10.1038/nature06005

[3] Rutgeerts, P., Feagan, B.G., Lichtenstein, G.R., et al. (2004) Comparison of Scheduled and Episodic Treatment Strategies of Infliximab in Crohn's Disease. Gastroenterology, 126, 402-413. https://doi.org/10.1053/j.gastro.2003.11.014

[4] Schnitzler, F., Fidder, H., Ferrante, M., et al. (2009) Mucosal Healing Predicts LongTerm Outcome of Maintenance Therapy with Infliximab in Crohn's Disease. Inflammatory Bowel Diseases, 15, 1295-1301. https://doi.org/10.1002/ibd.20927

[5] Allen, P.B., Lindsay, H. and Tham, T.C. (2010) How Do Patients with Inflammatory Bowel Disease Want Their Biological Therapy Administered? BMC Gastroenterology, 10, 1. https://doi.org/10.1186/1471-230X-10-1

[6] Vavricka, S.R., Bentele, N., Scharl, M., et al. (2012) Systematic Assessment of Factors Influencing Preferences of Crohn's Disease Patients in Selecting an Anti-Tumor Necrosis Factor Agent (CHOOSE TNF TRIAL). Inflammatory Bowel Diseases, 18, 1523-1530. https://doi.org/10.1002/ibd.21888

[7] Satsangi, J., Silverberg, M.S., Vermeire, S., et al. (2006) The Montreal Classification of Inflammatory Bowel Disease: Controversies, Consensus, and Implications. Gut, 55, 749-753. https://doi.org/10.1136/gut.2005.082909

[8] Chilton, F. and Collett, R.A. (2008) Treatment Choices, Preferences and DecisionMaking by Patients with Rheumatoid Arthritis. Musculoskeletal Care, 6, 1-14. https://doi.org/10.1002/msc.110

[9] William, E.L. and Edward, C.J. (2006) Patient Preferences in Choosing Anti-TNF Therapies-R1. Rheumatology (Oxford), 45, 1575-1576. https://doi.org/10.1093/rheumatology/kel369

[10] Jackson, C.A., Clatworthy, J., Robinson, A., et al. (2010) Factors Associated with Non-Adherence to Oral Medication for Inflammatory Bowel Disease: A Systematic Review. The American Journal of Gastroenterology, 105, 525-539. https://doi.org/10.1038/ajg.2009.685

[11] Selinger, C.P., Eaden, J., Jones, D.B., et al. (2013) Modifiable Factors Associated with Nonadherence to Maintenance Medication for Inflammatory Bowel Disease. Inflammatory Bowel Diseases, 19, 2199-2206.

https://doi.org/10.1097/MIB.0b013e31829ed8a6 


\section{Appendix 1. Questionnaire on Patients Preferences Regarding Biological Therapy}

Questionnaire on patients' preferences regarding biological therapy

1. Gender (male/female):

2. Type of IBD disease (Crohn's disease/ulcerative colitis):

3. Age:

4. Year of diagnosis:

5/a Localisation of Crohn's disease (small intestine, large intestine, both):

5/b Extension of ulcerative colitis (proctitis/left sided/pancolitis):

7. Current smoking history (never/yes, before/yes, currently):

8. Highest degree of education:

9. Have You ever been operated due to IBD?

If yes, how many times?

What kind of operations did You have?

10. Do You receive currently biological treatment?

If yes, which anti-TNF-alfa medication do You receive?

11. Have You ever received before biological treatment?

If yes, which anti-TNF-alfa medication have You received?

If yes, how many 1 year period have you received?

12. Was it needed to change biological treatment during biological therapy?

If yes, from which to which?

If yes, why was the therapy changed (loss of efficacy/allergy/other)?

13. Are you satisfied with your current therapy?

If no, why not?

14. If biological therapy was changed, which were you more satisfied with?

Why?

15. What do you think how expensive one biological treatment?

In case of Remicade?

In case of Humira?

16. When and from who did you hear at first time about the biological therapy?

17. What is your biggest problem with your biological treatment?

18. If you are on Remicade therapy,

the length of the therapy disturb you?

the intravenous regimen disturb you?

would you prefer subcutaneous injection, but every second week?

19. If you are on Humira therapy,

do You give injection yourself? If no, who helps you?

are You satisfied with subcutaneous injection?

every week or every second week injection disturb you?

would you prefer every $8^{\text {th }}$ week administer biological therapy, but intravenously?

20. Do you have any fear of biological therapy?

If yes, why? 
21. How do you remember, in which week did you feel the therapy's effect?

22. Did you feel any symptoms which meant you that before the next infusion /injection the therapy's effect decreased?

23. What was your worst experience during the biological treatment?

24. Did you experience any side effect of therapy?

If yes, with which therapy?

What kind of side effects did you experience?

25. If you would have the choice to choose biological therapy now, which would you choose?

Why?

26. From who/where do you get information about biological therapy? (physician, internet, friend, books, other)?

27. In the last year how many times did you visit your gastroenterologist physician because of biological therapy?

28. What kind of other therapy do you take regularly because of Your IBD?

29. Until now, which therapy was the most effective? You can choose any of your medication.

30. Have you been operated from the start of the biological therapy?

If yes, on which treatment were you at the time of the operation?

31. Would you like to participate in a new study drug trying, if your current therapy should be quitted?

Date:

Thank you for answering this questionnaire!

\section{Scientific Research Publishing}

Submit or recommend next manuscript to SCIRP and we will provide best service for you:

Accepting pre-submission inquiries through Email, Facebook, LinkedIn, Twitter, etc. A wide selection of journals (inclusive of 9 subjects, more than 200 journals) Providing 24-hour high-quality service User-friendly online submission system Fair and swift peer-review system Efficient typesetting and proofreading procedure Display of the result of downloads and visits, as well as the number of cited articles Maximum dissemination of your research work

Submit your manuscript at: http://papersubmission.scirp.org/

Or contact health@scirp.org 